\title{
Kajian Tingkat Pencemaran Minyak Bumi Akibat Pengeboran llegal Berdasarkan Pemetaan Sungai Sumur Dan Fisika-Kimia Air Studi Kasus : Kecamatan Keluang Kabupaten Musi Banyuasin Sumatera Selatan
}

\author{
Harnani ${ }^{1}$ \\ ${ }^{1} J u r u s a n$ Teknik Geologi, Universitas Sriwijaya
}

\begin{abstract}
Abstrak
Pencemaran air merupakan hal yang dapat mempengaruhi lingkungan hidup, terutama pada kesehatan dan kebersihan lingkungan sekitar. Kecamatan Keluang Kabupaten Musi Banyuasin Sumatera Selatan dikenal memiliki sumur-sumur pengeboran minyak bumi ilegal yang mana dilakukan tidak sesuai standarisasi yang umum dilakukan, sehingga di khawatirkan mencemari daerah sekitarnya. Penelitian ini bertujuan untuk mengkaji dan mengetahui dampak pencemaran lingkungan akibat pengeboran ilegal oleh masyarakat setempat, serta memberikan informasi hasil penelitian kepada pemerintah dan polisi untuk bekerja sama dalam menegakkan undang-undang yang telah ditetapkan. Untuk mengetahui tingkat pencemaran menggunakan metode penelitian yaitu pemetaan sungai dan sumur meliputi deskipsi karakteristik fisik air, berupa warna, rasa, bau, pengambilan contoh sample untuk analisa kandungan fisika-kimia air, dan proyeksi tingkat kesehatan masyarakat. Hasil dari identifikasi fisik air sebanyak 8 sampel dinyatakan tercemar. Pengambilan sampel melihat ketentuan pada perubahan fisik baik pada sungai maupun sumur, hasil dari analisis fisika-kimia air, yang ditemukan banyak senyawa kimia yang melebihi standar, $\mathrm{pH}$ yang didapat berkisar antara 6,258,16 dan jenis air tanah garam (TDS 31-464 mg/L), kenaikan nilai $\mathrm{pH}$ dan TDS diasumsikan akibat limbah air asin hasil dari pengeboran minyak bumi illegal, dan dengan adanya senyawa kimia baik utama maupun aksesoris yang berlebihan pada air maka dapat mempengaruhi kesehatan, dimana hal tersebut dibuktikan dengan hasil proyeksi tingkat kesehatan masyarakat dari tahun 2016 sampai sekarang yang terus menurun. mengacu pada Keputusan Menteri Negara Lingkungan Hidup Nomor : 115 Tahun 2003 tentang Pedoman Penentuan Status Mutu Air Menteri Negara Lingkungan Hidup menggunakan metode STORET dengan skor 16 (tercemar sedang).
\end{abstract}

Katakunci: : Minyak bumi, air asin, pH, TDS, proyeksi penyakit dan indeks pencemaran.

\section{Pendahuluan}

Pencemaran lingkungan terutama air yang dijadikan sebagai sumber kehidupan perlu diperhatikan dan diantisipasi dengan baik, lebihlebih terhadap air sungai, karena air sungai dipakai penduduk untuk berbagai keperluan. Pencemaran sungai oleh air buangan ditinjau dari sudut mikrobiologi antara lain : pencemaran bakteri patogen dan non patogen serta bahan organik. Banyaknya bahan organik akan merangsang pertumbuhan mikroorganisme menjadi pesat. Hal ini mengakibatkan pemakaian oksigen akan cepat dan meningkat, akibatnya kadar oksigen terlarut dalam air akan menipis dan menjadi sedikit sekali, yang akhirya mengakibatkan mikroorganisme dan organisme air lainnya yang memerlukan oksigen mati. Ekologi air akan berubah drastis. Keadaan menjadi anaerobik, sehingga air sungai busuk, dan tidak sehat bagi pertumbuhan mikroorganisme flora dan fauna air itu.

Korespodensi Penulis: (Harnani) Jurusan Teknik Geologi, Fakultas Teknik, Universitas Sriwijaya. Kawasan Kampus Terpadu UNSRI, Indralaya Utara, Sumatera Selatan.

Email: harnanistmt@gmail.com
Lingkungan hidup yang demikian ini sudah rusak dan tidak layak lagi bagi kebutuhan hidup kita (Ardhana, 1994).

Michael (1990), Pencemaran Air adalah Penyimpangan sifat-sifat air dari keadaan normal, bukan dari kemurniannya. Banyak air tawar yang tercemar berat oleh sisa-sisa pembuangan kotoran dan cairan pembuangan limbah rumah tangga ke dalam sungai.

Musi Banyuasin (Muba) Kecamatan Keluang Desa Sp6 merupakan wilayah yang memiliki potensi minyak dan gas bumi yang telah ditemukan sejak zaman belanda yang diperkirakan ada sekitar 1.500 sumur tua dan sekitar 500-an sumur dikelola warga sekitar secara swadaya dengan cara tradisional. Perangkap minyak dan gas bumi di daerah penelitian dikontrol oleh Antiklin Keluang yang berada pada Formasi Airbenakat dengan perselingan batulempung,serpih,batulanau, dan batupasir sebagai sourock yang kemudian terakumulasi ke suatu tempat yang memiliki porositas dan permeabilitas yang baik.

Oleh karena itu, melihat pencemaran yang terjadi pada masyarakat mengenai lingkungan hidup akibat dari hasil pengeboran minyak bumi oleh 
Karena itu membuang limbah pengeboran sehingga mencemari air dan tanah dengan mencacuh (Peraturan Menteri Kesehatan Republik Indonesia Nomor: 492/Menkes/Per/IV/2010) yaitu, mengenai persyaratan kualitas air minum agar air minum tidak menimbulkan gangguan kesehatan.

Lokasi penelitian secara administratif terletak pada Desa SP6, Kecamatan Keluang, Kabupaten Musi Banyuasin, Provinsi Sumatera Selatan, pada koordinat Geografis $103^{0} 54^{\prime} 59.3^{\prime \prime}$ Bujur Timur dan $02^{\circ} 38^{\prime}$ 56.4" Lintang Selatan. Luas daerah telitian kurang lebih $30 \mathrm{Km}^{2}(15 \times 15$ $\mathrm{km}$ ) dalam pengamatan sungai dan sumur. Lokasi penelitin dapat dijangkau melalui jalur darat menggunakan roda dua dan roda empat dengan jarak tempuh kurang lebih 4 jam dari kota Palembang (Tabel 1).

Berdasarkan pengamatan citra menggunakan Google Eart dan pengamatan lapangan, morfologidaerah telitian merupakan dataran rendah dan tidak ada singkapan yang ditemuakan, dari hasil pengamatan Peta Geologi lembar Palembang Sumatera Selatan (S.Gafoer dkk, 1995) Formasi batuan pada daerah telitian yaitu, Formasi Airbenakat (Tma), Anggota Perselingan Batulempung dengan Serpih da Lanau, bersisipan Batupasir (Gambar 1). Berdasarkan Peta Hidrogeologi lembar Palembang (H.M. Suryaman 2001) pada lokasi penelitian termasuk Akuifer produktif kecil umumnya dapat di jumpai pada daerah pelapukan dan rekahan. (Gambar 2).

\section{Metode Penelitian}

\section{Observasi Peta}

Metode yang pertama dalam proses penelitian yaitu melakukan pengamatan beberapa peta yaitu : Peta Gologi, Peta Morfologi (data SRTM), Google Earth dan Pata Hidrogeologi, setelah dilakukan analisis pada masing-masing peta agar dapat mengkorelasikan aspek geologi dengan pencemaran akibat pengeboran.

\section{Pengambilan Sampel}

Pengambilan sampel dilakukan pada jam 09.00 pagi dengan menggunakan botol SNI sejumlah 16 botol, 8 botol untuk analisa FisikaKimia air dan 8 untuk analisa Biologi. Pengambilan sampel melihat aspek fisik air baik itu sungai maupun sumur yang telah tercemar melalu parameter bau, warna dan rasa sehingga di dapatkanlah 8 sampel yang akan di lakukan analisis lebih lajut (Gambar 3).

\section{Analisis Laboratorium}

Analisis laboratorium kimi-fisika Air dilakukan di Laboratorium Dinas Lingkugan Hidup
Kabupaten Musi Banyuasin ( No.660/126/SHU$\mathrm{LLK} / \mathrm{VI} / \mathrm{DLH} / 2017$ ) dalam analisis sempel mengunakan Metode manual alat (PCSTestr 35 dan Lakmus) untuk pengukuran $\mathrm{pH}$ dan TDS dan SNI yang telah terakreditasi seperti Laminar Air Flow (LAF) dan Atomic Absorption Analysis (AAA) untuk mengukur unsur seperti Sulfat $\mathrm{SO}^{4}$, Besi $(\mathrm{Fe})$ terlarut, Mangan $(\mathrm{Mn})$ terlarut dan $\mathrm{E}$ Coli total.

Hasil dari pengujian sifat fisik dan kimia-fisika air, akan mengacu pada Keputusan (Menteri Negara Lingkungan Hidup Nomor 19 Tahun 2010) tentang Baku Mutu Air Limbah Bagi Usaha Dan/Atau Kegiatan Minyak Dan Gas Serta Panas Bumi. Metode yang telah dilakukan akan dijadikan sebagai data dalam penentuan Status Mutu Air yang nantinya dapat menunjukkan kondisi air apakah tercemar atau tidak. Menurut Keputusan Menteri Negara Lingkungan Hidup Nomor : 115 Tahun 2003 tentang Pedoman Penentuan Status Mutu Air Menteri Negara Lingkungan Hidup menggunakan metode STORET yaitu dengan membandingkan antara data kualitas air dengan baku mutu air yang disesuikan dengan peruntukannya guna untuk menentukan status mutu air, dengan cara menentukan status mutu air adalah dengan menggunakan sistem nilai dari "US-EPA (Environmental Protection Agency)" dengan mengklasifikasikan mutu air dalam empat kelas, yaitu :

1. Kelas A (Baik Sekali) Skor 0 (Memenuhi Baku Mutu)

2. Kelas $B$ (Baik) Skor $-1 \mathrm{~s} / \mathrm{d}-10$ (Tercemar Ringan)

3. Kelas B ( Sedang) Skor -11 s/d -30 (Tercemar Sedang)

4. Kelas C (Buruk) Skor >-31 (Tercemar Berat)

\section{Data}

Penelitian ini menggunakan beberapa data yaitu pengambilan sampel dilapangan sehingga didapatkan sebanyak 8 sampel, data hasil identifikasi fisik air, (tabel 01) data hasil uji yang dilakukan di laboratorium dinas lingkungan hidup kabupaten Musi Banyuasin, dan data-data yang dijadikan standarisasi baku mutu pencemaran air.

\section{Hasil dan Pembahasan}

\section{Geologi dan hidrogeologi daerah telitian}

Berdasarkan hasil pengamatan lapangan bahwa tidak ditemukan singkapan batuan namun peneliti memanfaatkan hasil cating dari pengeboran yang dilakukan oleh masyarakat, beberapa jenis batuan dan endapan seperti 
batulanau, batulempung, batugamping, dan batupasir. Selain batuan ditemukan juga organisme-organisme laut yang diasumsikan sebagai sumber minyak bumi pada Desa Sp,6 Kecamatan Keluang. (Gambar 4)

Hasil analisis Peta Geologi bahwa daerah telitian merupakan kontrol struktur yang baik dan batuan yang memiliki porositas dan premeabelitas pada batuan yang memiliki sifat permeabel dan inpermeabel yang menjadi tempat berimigrasinya minyak dan gas bumi dibuktikan dengan adanya sumur bor pertamina (lukin) dengan adanya sumur bor tersebut masyarakat yang memiliki lahan perkebunan melakukan pengeboran yang tidak sesuai dengan hukum dan undang-undang perminyakan indonesia.

\section{Endapan daerah telitian}

Pada daerah telitian tersusun atas endapan Aluvial-Fluvial. Penyebaran satuan ini menyebar secara keseluruhan pada daerah telitian dan adanya kondisi sungai yang telah mengalami perubahan akibat dari proses pengeboran oleh masyarakat. Sehingga menyebabkan matinya aliran sungai dan mengalami pencemaran baik secara fisik maupun non-fisik (Gambar 5).

\section{Arah aliran sungai}

Sungai Kecamatan Keluang menyerupai pola aliran dan denritik dengan anak sungai bercabang seperti ranting yang mengarah barat laut. Sebagian sungai telah mengalami perubahan arah aliran diakibatkan oleh menumpuknya lumpur hasil dari pengeboran yang menutupi ruas pada sungai.

\section{Karakteristik fisik air}

Dari hasil pengamatan fisik air pada sungai keluang bulan juli 2017, terlihat pada air tergenangi oleh minyak bumi serta adanya pengaruh air formasi sehingga menyebabkan perubahan warna air sungai yang signifikan. Sedangkan, untuk pengamatan bau dapat dikategorikan tidak berbau sampai sangat berbau terutama lokasi sungai yang berada didekat pengeboran minyak bumi oleh masyarakat identikasi dilakukan pada saat musim panas sedang berlangsung sehingga tidak berpengaruh dalam perubahan warna pada air sungai. Selanjutnya mengenai rasa pada air yang didapatkan adalah payau sampai asin.

\section{Karakteristik fisika dan kimia}

Analisis semua sampel dilakukan untuk mengetahui karakteristik fisika-kimia air yang dilakukan di Laboratorium Dinas Lingkungan Hidup Musi Banyuasin (No. 660/ 126/ SHU-
LLK/VI/DLH/2017) dilakukan pada tanggal 14 juni-04 juli 2017 dengan no sampel 61-68. Analisis ini mengacu pada keputusan Peraturan Menteri Kesehatan Republik Indonesia (Nomor: 492/Menkes/Per/IV/2010) yaitu, mengenai persyaratan kualitas air minum agar air minum tidak menimbulkan gangguan kesehatan, keputusan (Menteri Negara Lingkungan Hidup Nomor 19 Tahun 2010) tentang Baku Mutu Air Limbah Bagi Usaha Dan/Atau Kegiatan Minyak Dan Gas Serta Panas Bumi, dan Menurut Keputusan Menteri Negara Lingkungan Hidup Nomor : 115 Tahun 2003 tentang Pedoman Penentuan Status Mutu Air Menteri Negara Lingkungan Hidup menggunakan metode STORET.

Dari hasil analisis sungai disimpulkan bahwa pada jenis penguji fisika jumlah zad padat terlarut memenuhi standar yang diperssyaratkan, sedangkan pada uji kimia tidak memenuhi standar yang telah ditetapkan. Kmadar yang melebihi kadar maksimum yang diperbolehkan yaitu: kadar Besi terlarut (Fe) 12,74 mg/L dari yang seharusnya $0.3 \mathrm{mg} / \mathrm{L}$, Mangan $(\mathrm{Mn})$ yaitu 0,57 dari yang seharusnya 0,4 mg/L, $\mathrm{pH} \mathrm{8,16}$ dari yang seharusnya 6,5-8 (Tabel 2).

\section{Tingkat Pencemaran Air}

Penentuan apakah air sungai tersebut telah tercemar atau tidak, dapat dilakukan dengan analisis nilai pada parameter yang telah didapatkan. Untuk mengetahui lebih lanjut dalam penentuan lingkungan perairan mengacu pada Keputusan Menteri Negara Lingkungan Hidup Nomor : 115 Tahun 2003 tentang Pedoman Penentuan Status Mutu Air Menteri Negara Lingkungan Hidup menggunakan metode STORET. Penentuan status mutu air dengan menggunakan metoda STORET dengan melakukan perhitungan pada nilai maksimum, minimum, dan rata-rata dari data-data hasil yang di dapatkan skor 16 yang termasuk kelas C Tercemar Sedang. (Tabel 3 dan Tabel 4)

\section{Kesimpulan}

Berdasarkan Analisis dan Penelitian dapat disimpulakan bahwa:

a. Secara Geologi pada daerah telitian merupakan tempat terakumulasinya minyak dan gas bumi yang ditinjau dari aspek litologi dan kontrol struktur yang berkerja.

b. Masyarakat setempat sulit dalam menggunakan atau memanfaatkan air sungai dikarenakan adanya pencemaran oleh pengeboran ilegal 
c. Sistem alur sungai mengalami kerusakan dan tidak dapat berfungsi dengan semestinya

d. Secara keseluruhan sungai tercemar sedang

Kemudian Penulis memberikan saran sebagai berikut:

a. Pemerintah dan pihak penegak hukum perlu menertibkan sesuai dengan Undang-Undang yang berlaku

b. Perlu dilakukan evaluasi dan rehabilitas pada sungai yang telah mengalami pencemaran

c. Pemerintah memberiakan himbauan atau sosialisasi pentingnya dalam menjaga lingkungan sekitar dan sungai.

\section{Ucapan Terimakasih}

Ucapan Terimakasih Kepada staff dan jajaran Dinas Lingkungan Hidup, Musi Banyuasin. Tarimakasih kepada masyarakat dan kelurahan Keluang yang telah membantu dalam proses penelitian. Terimakasih kepada mahasiswa yang sudah membantu dalam pengambilan data

\section{Daftar Pustaka}

Anonim. 2010. Peraturan Menteri Kesehatan Republik Indonesia Nomor: 492/Menkes/Per/IV/2010 Tentang persyaratan kualitas air minum agar air minum tidak menimbulkan gangguan kesehatan.

Anonim. 2003. Peraturan Menteri Negara Lingkungan Hidup Nomor : 115 Tahun 2003 tentang Pedoman Penentuan Status Mutu Air Menteri Negara Lingkungan Hidup menggunakan metode STORET. H-160

Anonim. 2010. Keputusan (Menteri Negara Lingkungan Hidup Nomor 19 Tahun 2010) tentang Baku Mutu Air Limbah Bagi Usaha Dan/Atau Kegiatan Minyak Dan Gas Serta Panas Bumi

Ardhana, Made M., 1994, Mikrobiologi Air, Universitas Udayana, Bali. 


\section{Lampiran Gambar dan Tabel}
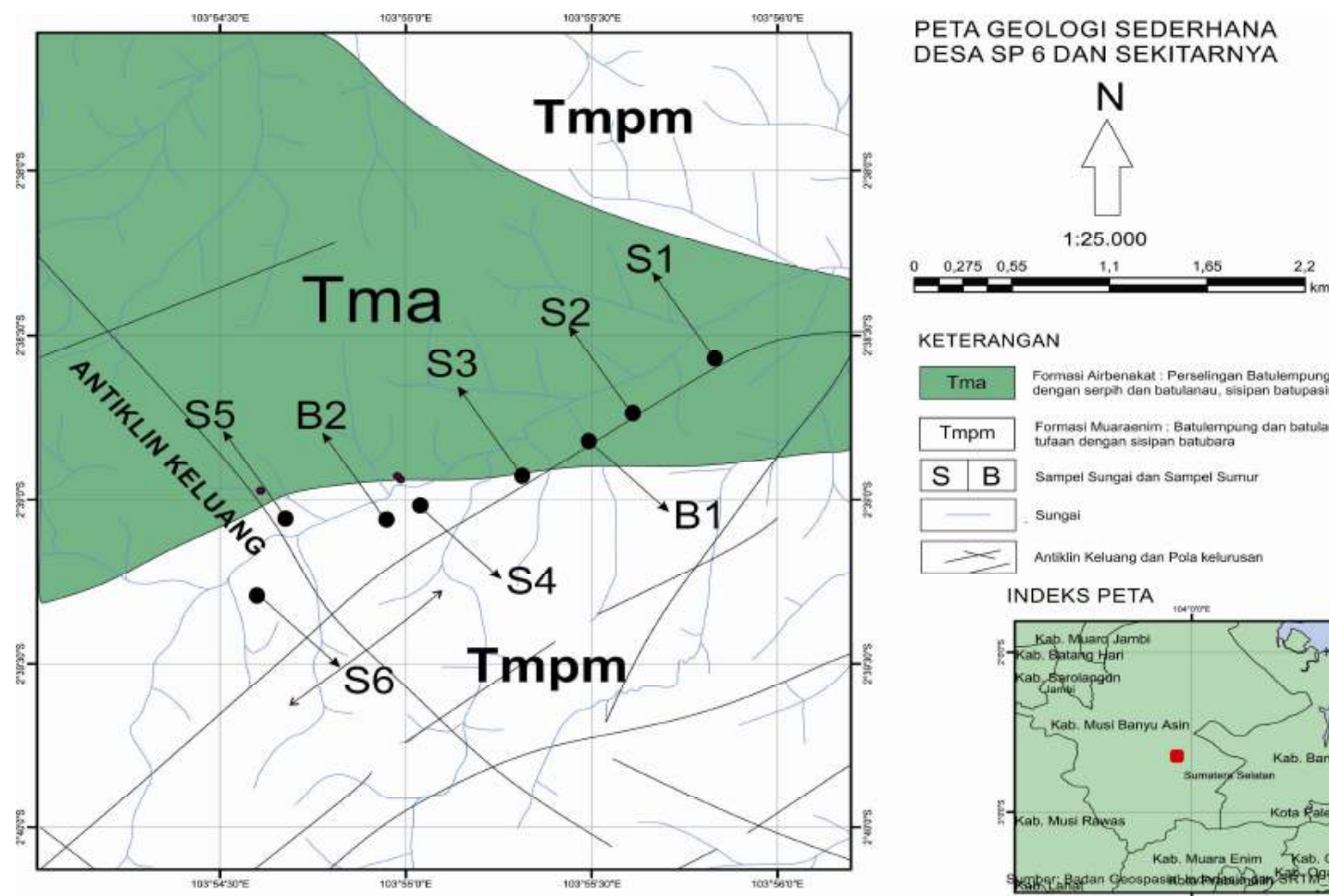

KETERANGAN

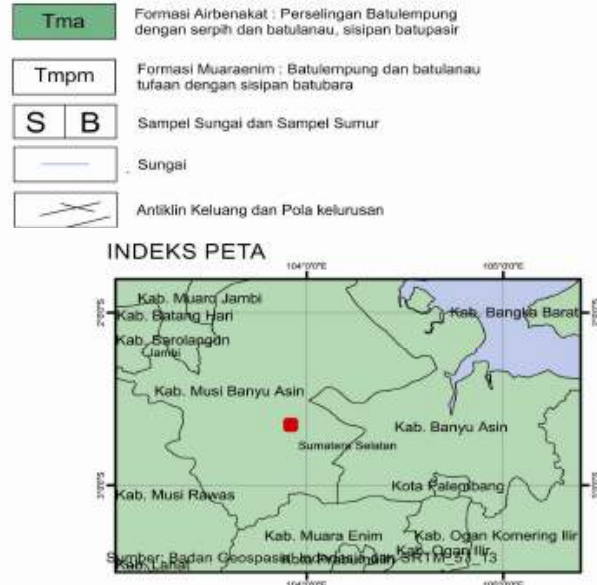

Gambar 1. Peta Geologi Lokasih Pengamatan Desa SP6, Kecamatan Keluang, Sumatera Selatan

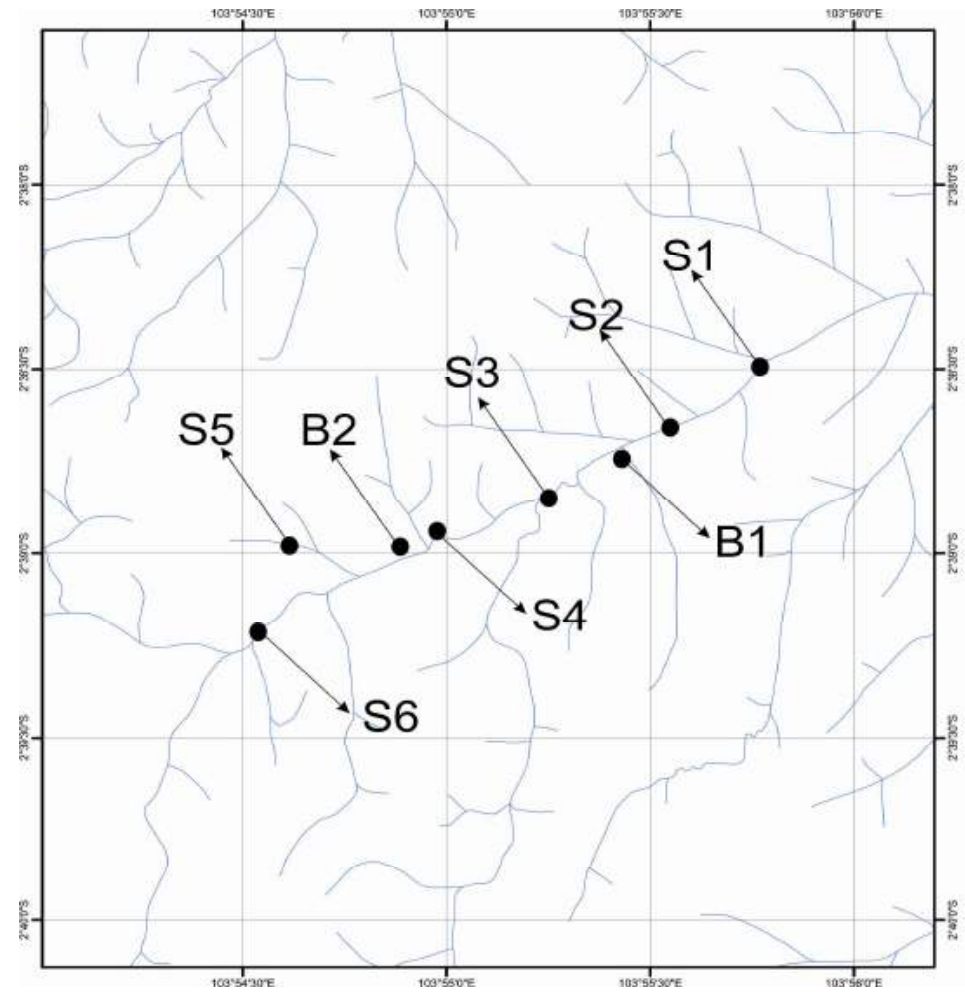

PETA LINTASAN SEDERHANA DESA SP 6 DAN SEKITARNYA

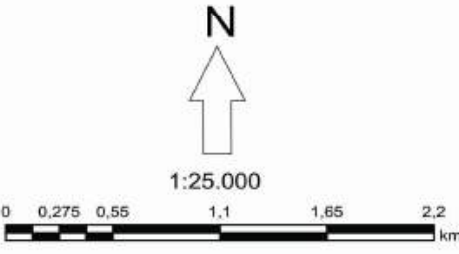
KETERANGAN
S SUNGAI_LN_50K
B SAMPEL SUMUR

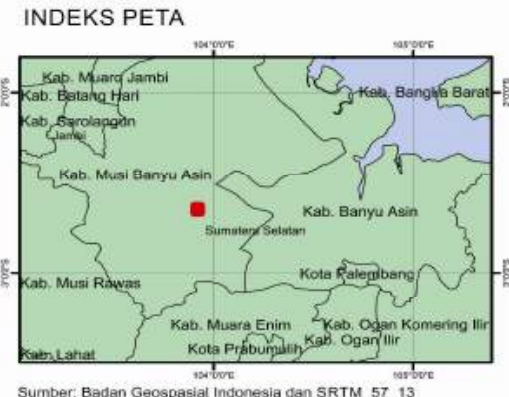

Gambar 2. Peta Lintasan daerah telitian dan sekitarnya 

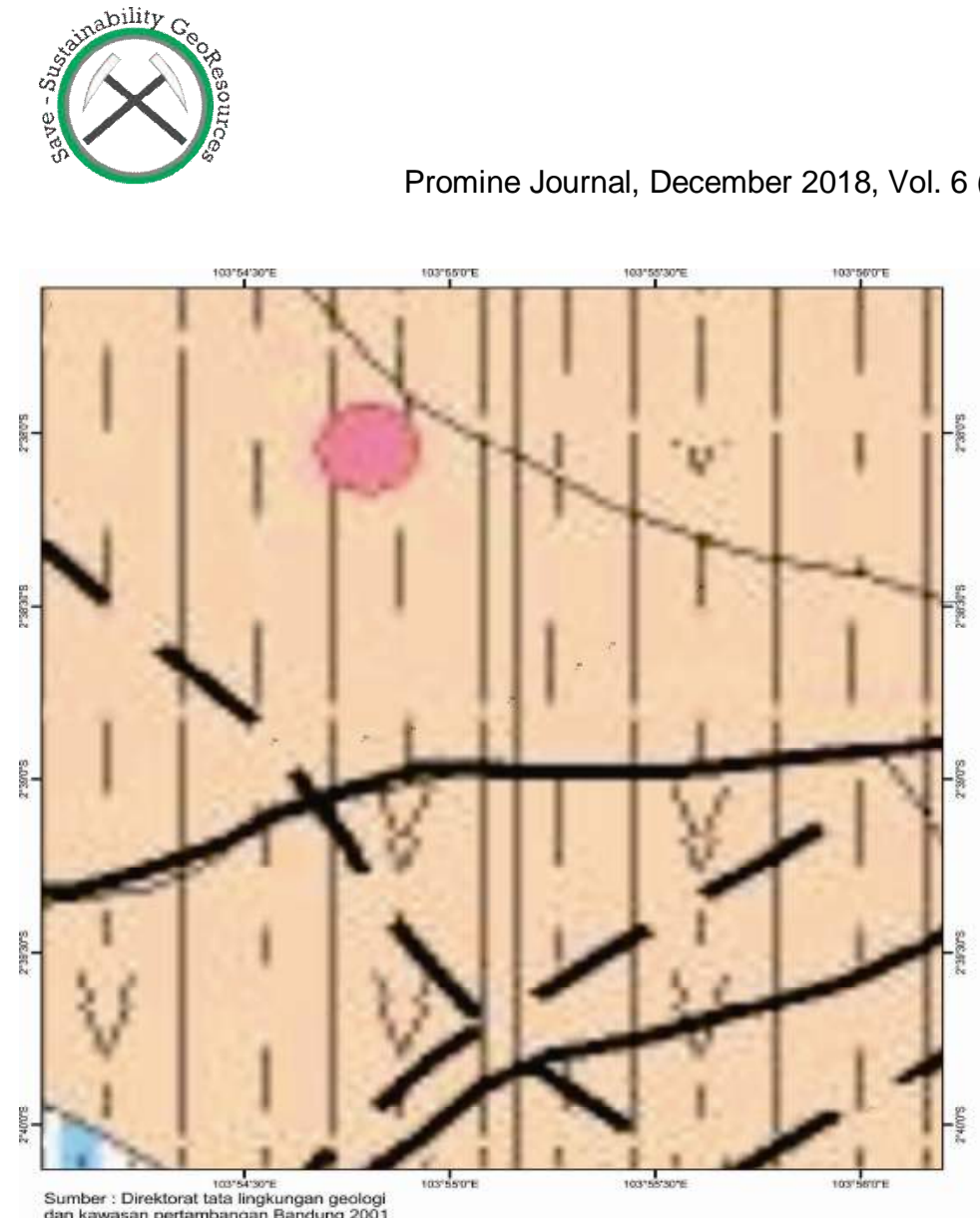

PETA HIDROGEOLOGI SEDERHANA DESA SP 6 DAN SEKITARNYA

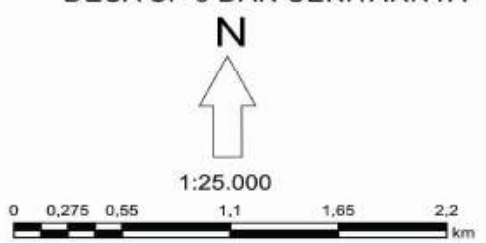

KETERANGAN

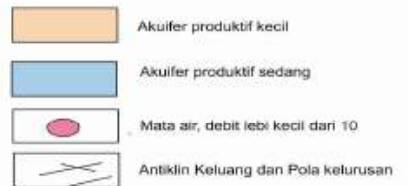

Gambar 4. Peta hidrogeologi

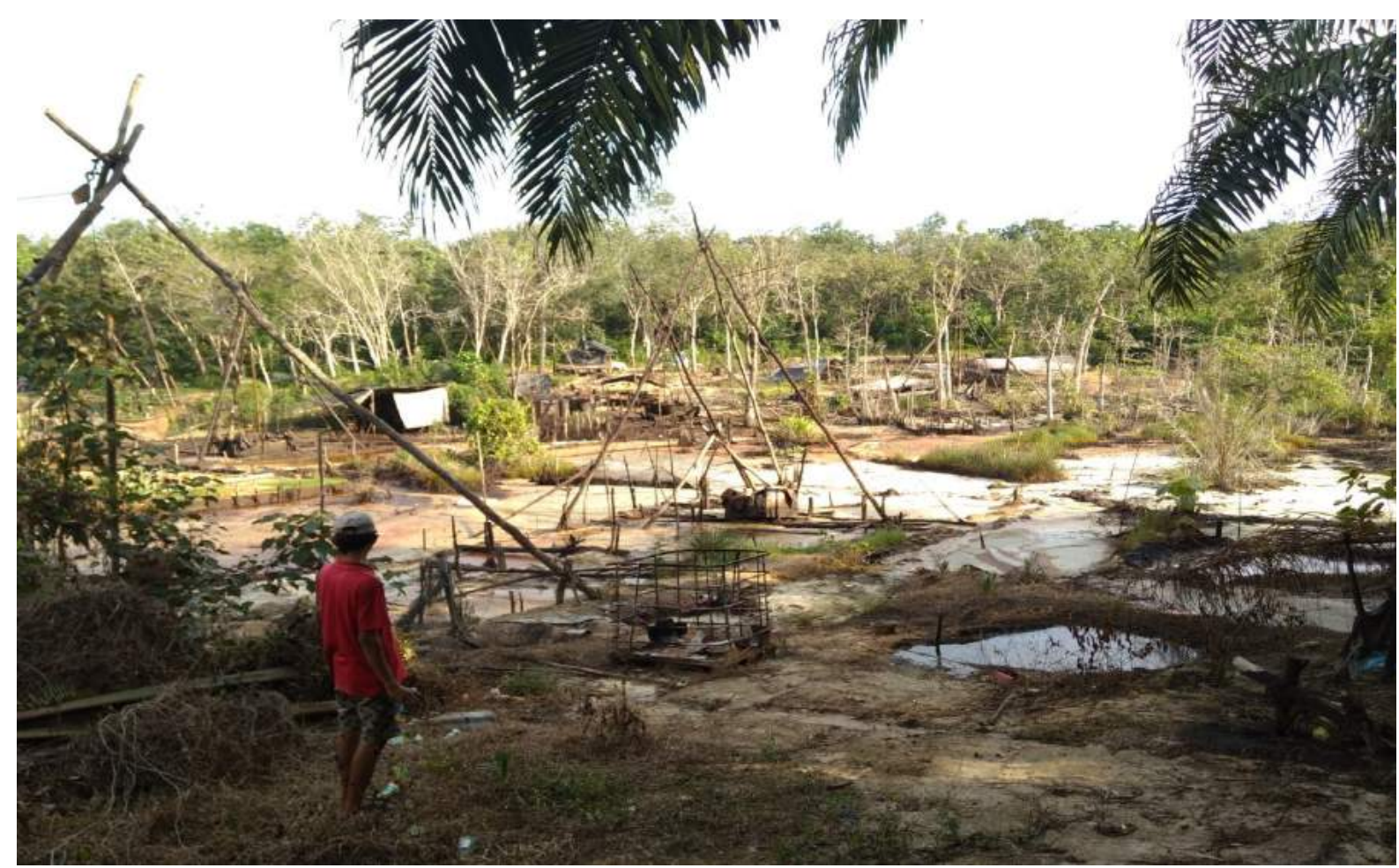

Gambar 5. Bentuk lahan endapan daerah telitian 
Tabel 1. Koordinat lokasi penelitian

\begin{tabular}{|c|c|c|c|c|c|c|}
\hline $\mathrm{NO}$ & LP & KOORDINAT & ELEVASI & WARNA & $\mathrm{BAU}$ & RASA \\
\hline & & S02 38' 29.1"E103 55' & & & & \\
\hline 1 & S1 & $\begin{array}{c}46.6^{\prime \prime} \\
\text { S02 38' 40.2"E103 55' }\end{array}$ & 17 & TERCEMAR & BERBAU & PAYAU \\
\hline 2 & S2 & $\begin{array}{c}32.1 " \\
\text { S02 38' 43.9"E103 55' }\end{array}$ & 20 & TERCEMAR & TIDAKBERBAU & ASIN \\
\hline 3 & S3 & $\begin{array}{c}26.6^{\prime \prime} \\
\text { S02 38' 50.4"E103 55' }\end{array}$ & 16 & TERCEMAR & BERBAU & PAYAU \\
\hline 4 & S4 & $\begin{array}{c}15.7^{\prime \prime} \\
\text { S02 38' 55.9"E103 54' }\end{array}$ & 18 & TERCEMAR & BERBAU & ASIN \\
\hline 5 & S5 & $\begin{array}{c}59.1 " \\
\text { S02 38' 57.6"E103 54' }\end{array}$ & 24 & TERCEMAR & BERBAU & ASIN \\
\hline 6 & S6 & $\begin{array}{c}51.3^{\prime \prime} \\
\text { S02 38' 58.6"E103 54' }\end{array}$ & 27 & TERCEMAR & BERBAU & PAYAU \\
\hline 7 & B1 & $\begin{array}{c}36.3^{\prime \prime} \\
\text { S02 39' 13.2"E103 54' }\end{array}$ & 22 & TERCEMAR & BERBAU & ASIN \\
\hline 8 & B2 & $32.6 "$ & 12 & TERCEMAR & BERBAU & ASIN \\
\hline
\end{tabular}

Tabel 2. Hasil Analisi Laboratorium

\begin{tabular}{|c|c|c|c|c|c|c|c|}
\hline \multirow{2}{*}{ No. } & \multirow{2}{*}{ Parameter Uji } & \multirow{2}{*}{ Satuan } & \multicolumn{4}{|c|}{$\begin{array}{l}\text { Hasil Analisa } \\
\end{array}$} & \multirow{2}{*}{ Metode Uji } \\
\hline & & & 61.14.06.2017 & \begin{tabular}{|l|}
62.14 .06 .2017 \\
\end{tabular} & 63.14.06.2017 & 64.14 .06 .2017 & \\
\hline & Fisika & & & & & & \\
\hline \multirow[t]{2}{*}{1} & TDS & $\mathrm{mg} / \mathrm{l}$ & 47 & 63 & 77 & 67 & Manual Alat \\
\hline & Kimia & & & & & & \\
\hline 1 & $\mathrm{pH}^{*}$ & $\#$ & 7,63 & 7,24 & 7,35 & 6,25 & SN1 06-6989011-2004 \\
\hline 2 & Sulfat $\left(\mathrm{SO}_{4}\right)$ & mgl & 1 & 19 & 26 & $!$ & Manuel Abet \\
\hline 3 & Besi (Fe) Terlarut & $\mathrm{mg} / \mathrm{l}$ & 3,86 & 0,69 & 7,75 & 4,76 & SN1 698942009 \\
\hline 4 & Mangan (Mn) Terlarut & $\mathrm{mg} / \mathrm{l}$ & $<0,024$ & 40,024 & 0,12 & 40,024 & SNI 6989.5 .2009 \\
\hline 5 & E-Coli Total & $1100 \mathrm{ml}$ & 1100 & $>2400$ & 93 & 1100 & SNI 01 2897.1992 \\
\hline & & & & & & & \\
\hline \multirow[t]{2}{*}{ No. } & Parameter Uji & Satuan & \begin{tabular}{|l|}
65.14 .06 .2017 \\
\end{tabular} & \begin{tabular}{r|}
\multicolumn{2}{|c}{ Hasil A } \\
66.14 .06 .2017 \\
\end{tabular} & \begin{tabular}{|l|} 
Analisa \\
67.14 .06 .2017 \\
\end{tabular} & $68.14,06.2017$ & Metode Uji \\
\hline & Fisika & & & & & & \\
\hline \multirow[t]{2}{*}{1} & TDS & $\mathrm{mg} / \mathrm{l}$ & 269 & 31 & 464 & 460 & Manual Alat \\
\hline & Kimia & & & & & & \\
\hline 1 & $\mathrm{pH}^{*}$ & $\#$ & 8,16 & 6,79 & 7,74 & 7,31 & SNI 06-6989.11-2004 \\
\hline 2 & Sulfat $\left(\mathrm{SO}_{4}\right)$ & $\mathrm{mg} / \mathrm{l}$ & 36 & 30 & 4 & 3 & Manual Alat \\
\hline 3 & Besi (Fe) Terlarut & $\mathrm{mg} / \mathrm{l}$ & 7,20 & 12,74 & 5,21 & 2,76 & SNI 6989.4 .2009 \\
\hline 4 & Mangan (Mn) Terlarut & $\mathrm{mg} / \mathrm{l}$ & 40,024 & 0,10 & 0,57 & 0,08 & SN1 6989.52009 \\
\hline 5 & E-Coli Total & $1100 \mathrm{ml}$ & 120 & 64 & $>2400$ & 75 & SNI 01.2897 .1992 \\
\hline
\end{tabular}


Promine Journal, December 2018, Vol. 6 (2), page 16 - 23

Tabel 3. Penentuan sistem nilai untuk menentukan status mutu air

\begin{tabular}{clccc}
\hline \multirow{2}{*}{ Jumlah contoh $^{1)}$} & \multicolumn{3}{c}{ Nilai } & \multicolumn{3}{c}{ Paramete } \\
& & Fisika & Kimia & Biologi \\
\hline \multirow{3}{*}{$<10$} & Maksimu & -1 & -2 & -3 \\
& m & -1 & -2 & -3 \\
& Minimum & & & \\
& & -3 & -6 & -9 \\
& Maksimu & -2 & -4 & -6 \\
& m & -2 & -4 & -6 \\
& Minimum & -6 & -12 & -18 \\
\hline
\end{tabular}

abel 4. Hasil Status Mutu Kualitas Air

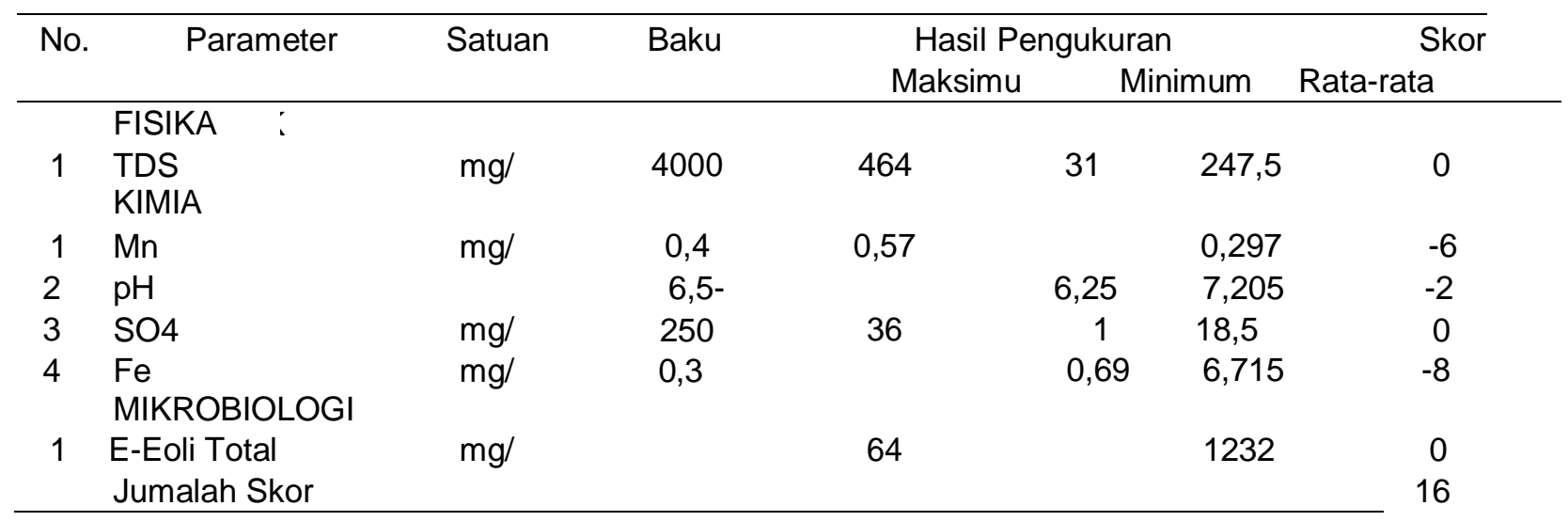

